\title{
Acupuncture and cupping alternative therapy in patients with acute low back pain
}

\begin{abstract}
Introduction: acupuncture and cupping constitute an alternative therapy to alleviate different conditions, especially acute low back pain, which improves the level of satisfaction and impacts on the quality of life of patients who suffer from it.

Objective: to evaluate the efficacy of treatment with acupuncture and cupping in patients with acute low back pain.

Methods: a randomized phase III therapeutic clinical trial was carried out in patients who attended the Natural and Traditional Medicine service of the rehabilitation room of the Juan Manuel Páez Inchauthi Polyclinic, in the municipality of Moa, Holguín province, Cuba, in the period of July to December of the year 2017.

The study universe consisted of 80 patients who attended the consultation; The sample was randomly selected and consisted of 60 patients in two study groups, group I, who received acupuncture treatment, and group II, with cupping, made up of 30 patients each. Both were diagnosed with post Bi syndrome. Results: men predominated in the study, with $63.3 \%$, and study group II, with $66.7 \%$. The age group from 40 to 49 years was the most affected. In both, the exogenous wind factor predominated. It was observed that the Bi wind syndrome is the most benefited with acupuncture therapy, as when the suction cup was applied.
\end{abstract}

Conclusion: in both groups there was $100 \%$ effectiveness of acupuncture therapy and the cupping, in the improvement or cure of acute low back pain.

Keywords: low back pain, acupuncture, cupping, Bi syndrome
Volume 6 Issue 3 - 202I

\section{Yamila Navarro Caboverde,' Graciela Córdova García, ${ }^{2}$ Hansel Salas Ferrer, ${ }^{3}$ Lidice Ruiz Benitez, ${ }^{3}$ Anabel Sánchez Saname ${ }^{4}$}

'Lic. Nursing, Higher education master, Assistant Professor and associate researcher, Subsidiary of Medical Sciences Tamara Bunke Bider, Moa, Holguin, Cuba

${ }^{2}$ Lic. Educaion, Higher education master, Assistant teacher, Holguín University of Medical Sciences, Subsidiary of Medical Sciences “Tamara Bunke Bider", General Training Department, Holguin, Cuba

${ }^{3}$ Lic. Nursing, Higher education master, Assistant Professor, Subsidiary of Medical Sciences Tamara Bunke Bider, Moa, Holguin, Cuba

${ }^{4}$ nnd degree specialist comprehensive general medicine, Assistant professor, Subsidiary of Medical Sciences Tamara Bunke Bider, Moa, Holguin, Cuba

Correspondence: MSc. Yamila Navarro Caboverde, Lic. Nursing, Higher education master, Assistant Professor and associate Researcher, Subsidiary of Medical Sciences Tamara Bunke Bider, Moa Holguin, Cuba, Email yncaboverde@infomed.sld.cu

Received: July 08, 202I | Published: November 25, 2021

\section{Introduction}

Pain is one of the symptoms that the doctor most frequently encounters in his daily practice; Its relief has been since ancient times one of the main objectives, so it is necessary to understand the dimension it has for those who suffer it. In conditions of the osteomyoarticular system, pain is the fundamental symptom and constitutes a situation of importance to be resolved for Medicine. The spinal column as the main axis of the body is subjected to weight bearing with different pressures and tensions, which can cause alterations, which can be difficult to treat.

There is a close relationship between the conditions of the osteomyoarticular system and the labor sphere. These disorders are not specific to developing countries, despite new technologies and work organization; they also have an impact on occupational health in industrialized countries. However, the reality for developing countries is much more severe, considering that the distribution of jobs is different, depending on the type of country. Eg: in England, only 2.5\% of the labor force is employed in agriculture, while in Africa, Asia and Latin America this is the main line. ${ }^{2}$

The structure of the economy defines a lot the workload and the risks in the work environment. About $40-80 \%$ of workers in developing countries and $10-20 \%$ in industrial countries are exposed to forced labor, especially in agriculture, industry and some services; not only because of the workload, but also because of the simultaneous exposures to heat, the risks of accidents, the presence of dust and chemical factors in the work areas. Furthermore, the effect of the forced labor burden is compounded by malnutrition and chronic and parasitic diseases. ${ }^{2}$

In Cuba, the behavior of acute low back pain is very similar to that of other countries, since it appears in $80 \%$ of men of working age and is the second cause of pain. In the province of Holguín, as in the rest of the country, there is consensus among experts that low back pain is a morbid process that affects the general population and young adults in particular, so efforts are being made to increase rehabilitation and social reintegration of this patients. ${ }^{3}$

The municipality of Moa, especially the health area of the Juan Manuel Páez Inchautis Teaching Polyclinic, does not escape this condition, since low back pain constitutes a serious health problem and more than $50 \%$ of its working population does it in mining and construction activities, which is why there is a high incidence of patients suffering from this ailment and it is once one of the most frequent causes of pain and reason for consultation, which has a negative impact on the age groups of 30 to 60 years.

There are multiple therapies to improve the symptoms of this condition, many of them unstable in the ambulatory pharmacy network, in some cases they are few accepted by patients due to their adverse reactions, in others they do not resolve the pain. However, the techniques of natural and traditional medicine constitute a healthy alternative in their recovery. With the aim of finding quick and effective therapeutic ways to alleviate or cure acute low back pain, it was decided to study the efficacy of cupping and acupuncture as one more option in the therapeutic arsenal of these patients. 


\section{Method}

A randomized controlled therapeutic clinical trial (Phase III) was carried out with the purpose of evaluating the efficacy of acupuncture and cupping treatment in patients with acute low back pain, diagnosed in the orthopedic consultation of the Juan Manuel Páez Community Polyclinic, in Moa, Holguín, Cuba, with a prior work agreement with the Natural and Traditional Medicine consultation of the rehabilitation room located in said institution in a period of 6 months (July December 2017).

\section{Universe and sample}

The universe consisted of 80 patients who attended the Natural and Traditional Medicine service diagnosed with acute low back pain in the aforementioned period. The sample, made up of 60 patients between 30 and 60 years of age of both sexes who met the inclusion criteria, selected by the simple random method and divided into two groups of 30 patients each; group I, made up of odd numbers, received acupuncture treatment, and group II, made up of even numbers, received treatment with cupping.

The following criteria were taken into account:

\section{Inclusion criteria}

a. Being between 30 and 60 years of age, with a diagnosis corresponding to acute low back pain (sudden onset of pain in the lumbosacral region).

b. Be mentally fit.

c. Acceptance by the patient to participate in the research.

\section{Exclusion criteria}

A. Pregnant patients.

B. Patients with dermatological disease at the sites of the points.

C. Patients with neoplasia associated with low back pain.

\section{Exit criteria}

i. Any patient who at some point did not wish to continue in the investigation.

ii. Patients who did not attend two or more treatment sessions.

iii. Patients who got worse after the 4th. Treatment session.

\section{Diagnostic criteria}

Western diagnosis: in order to carry out this study, the pertinent work coordination was established with the specialists in Orthopedics and Physiatry of said center, who diagnosed the patients with acute low back pain.

For this, the presence of pain, functional impotence, contracture of the paravertebral muscles and the results of the Lassegue maneuver (test of the elevation of the extended leg, with the patient in supine decubitus) were taken into account. Normally, there should be no pain or inability to lift and manages to create an angle of 900 with respect to the horizontal plane; in the pathological case, pain is created upon elevation of the limb at an angle of 450).

Oriental diagnosis: the oriental diagnosis was made by Bi syndrome, according to the exogenous pathogenic agent causing acute low back pain, for which methods such as observation, questioning, auscultation and palpation were used, elements collected in the medical history sheet.

\section{Treatment}

The principle of the treatment was simple: it was based on extracting the pathogenic factors that had invaded the channels and the stagnation of Qi and Xue was eliminated. It was aimed at removing the wind, removing moisture, and reducing cold.

Various literatures were reviewed and for the selection of the acupuncture points it was taken into account to carry out the oriental diagnosis individually for each patient, and according to the exogenous factor the following points were chosen: (4-6) Local points: VG3, VC4, V25, V23, VB30.

VG3.-In the midline of the back, below the spinous process of the fourth lumbar vertebra.

VC4.-It is the alarm point of the small intestine, in the anterior midline 4 cun below. VB30.-At the junction of the external third and the middle third between the distance of the greater trochanter and the YAO SHU point (VG2). It is located in lateral decubitus with the leg flexed (gallbladder), standing back, at the ankle.

V23.-SHU point of kidney, location 1.5 cun lateral to the lower border of the spinous process of the second lumbar vertebra, at the level of the lower border of the rib.

V25. - (bladder), SHU point of the large intestine, location 1.5 cun lateral to the lower border of the spinous process of the fourth lumbar vertebra, at the level of the superior border of the iliac crest.

Indication: Lower back pain, lower limb paralysis.

\section{Distal points:}

a) When irradiation occurs in the lower limbs (IG4) in the first and second metacarpals at their radial border.

b) When posterior irradiation occurs in the lower limbs (V40, V57).

c) V40, at the midpoint of the transverse fold of the popliteal muscle.

d) V57, where two gastrocnemius muscles join to form the Achilles tendon.

e) When anterior irradiation occurs in the lower limbs (E36, E41, E44).

f) E36, location of the thickness of a lower and lateral finger of the tuberosity of the tibia 0.3 cun, below the patella, outside the anterior border of the tibia.

g) E41, in front of the ankle, between the edges of the malleolus.

h) E44, 0.5 cun proximal to the interdigital junction of the second and third toes.

i) When lateral irradiation occurs in the lower limbs (VB34, V39).

j) VB34, in the anteroposterior depression of the fibular head.

k) V39, 3 cun above the lateral malleolus in the adjacent depression between the posterior border of the fibula and the tendons of the peroneal brevis muscle.

Bi syndrome refers to pain due to an obstruction of the meridians. This is due to external factors.

The external pathogenic factors that can produce this syndrome are: wind, cold, humidity and heat; also its combination. 
To unblock the circulation of energy and blood in the channels and collaterals of the lumbosacral region, it will be used in the following points: V25, V40, V39.

The variables used were: age, sex, predominant exogenous pathogenic factor (wind, humidity and cold), clinical evolution (cured and improved) and efficacy, according to type of treatment (effective and not effective)

\section{Patient evaluation criteria (5.6)}

Pain: to measure the degree of pain, the visual analog scale was used, which represented a graded scale of $0-10$, where zero $(0)$ signified absence of pain and point 10 , maximum pain; the patient marked on this scale the degree of intensity of pain before treatment and after. It was classified as: good (degree of pain between 0-3), fair (degree of pain between 4-6) and bad (degree of pain between 7-10).

Based on this assessment, the evaluation criterion carried out by the specialist in physiatry in the rehabilitation room was established, which classified the patients into three categories:

Cured: No pain or minimal pain, no functional impotence or contracture of the paravertebral muscles; Lassegue maneuver with amplitude of 90 to 100degrees.

Improved: mild or moderate pain, Lassegue maneuver with amplitude of 60 and 80 degrees, no functional impotence or contracture of the paravertebral muscles.

Not improved: pain of the same intensity as at the beginning of treatment, painful Lassegue maneuver at an angle of 45 degrees, with functional impotence; there is paravertebral contracture.

This assessment was carried out in 12 sessions, the time established to verify the evolution of the cases. It was evaluated in the 4th. 8th. and 12 th. Treatment sessions.

In this way, the treatment was considered to be:

Effective: when the patient achieved cure or improvement.

Not effective: when the patient failed to improve or heal.

To process the data, the statistical package Statistics Program for Social Sciences (SPSS) 20.0 (2011) was used, using the frequency distribution and contingency tables as statistical measure, for a confidence level of $95 \%$, and the X2 test. , for the independence between variable.

H0: There is an association between the variables.

H1: There is no association between the variables.

Decision criteria:

If $\mathrm{H} 0$ is accepted, there is an association

If $\mathrm{H} 0$ is rejected, there is no association

Where:

Significance level

Degrees of freedom (k-1) (m-1) m: number of columns k: number of rows oij: observed frequency eij: expected frequency $n$ : sample size.

The patients gave their informed consent for this research, approved by the Scientific Council. The authors did not present conflicts of interest.

\section{Results}

When characterizing the sample according to the variables sex and treatment groups Table 1, it was observed that in both groups the male sex predominated, with $63.3 \%$, and specifically study group II, with $66.7 \%$

As shown in Table 2, it was observed that in both groups the age of $40-49$ years prevailed, with $53.3 \%$ of the total of treated patients, followed by the age group of $50-59$, with $28,3 \%$.

Considering the exogenous factors, according to the Bi syndrome and treatment groups Table 3, it was observed that the exogenous factor Wind prevailed in both groups, with $66.7 \%$ of the total patients treated.

Taking into account the clinical evolution, according to the Bi syndrome and acupuncture treatment Table 4 , it was observed that the Bi Wind syndrome is the most beneficial, with $53.3 \%$ of patients cured. All patients studied were cured or improved with this treatment.

In Table 5 the clinical evolution of group II treated with a vacuum cup was observed, which shows that, according to $\mathrm{Bi}$ (Wind) syndrome, they were the most benefited with this technique in $63.3 \%$. All patients studied were cured or improved with this treatment.

Table I Patients with acute low back pain, according to sex and treatment groups

\begin{tabular}{lllllll}
\hline \multirow{2}{*}{ Sex } & \multicolumn{3}{c}{ Treatment groups } & \multicolumn{2}{c}{ Total } \\
\cline { 2 - 5 } & \multicolumn{2}{c}{ Group I } & \multicolumn{2}{c}{ Group II } & n & $\%$ \\
\cline { 2 - 5 } & $\mathbf{n}$ & $\%$ & $\mathbf{n}$ & $\%$ & & \\
\hline Male & 18 & 60 & 20 & 66,7 & 38 & 63,3 \\
Female & 12 & 40 & 10 & 33,3 & 22 & 36,7 \\
Total & 30 & 100 & 30 & 100 & 60 & 100
\end{tabular}

Source: Medical history, statistical package SPSS 20.0.

Table 2 Patients with acute low back pain, according to age and treatment groups Total

\begin{tabular}{lllllll}
\hline Age (years) & \multicolumn{2}{l}{ Treatment groups } & \multicolumn{3}{l}{ Total } \\
\hline & \multicolumn{2}{l}{ Group I } & \multicolumn{2}{c}{ Group II } & n & $\%$ \\
\hline & n & $\%$ & n & $\%$ & & \\
\hline $20-29$ & 2 & 6,6 & I & 3,3 & 3 & 5 \\
$30-39$ & 3 & 10 & 5 & 16,6 & 8 & 13,3 \\
$40-49$ & 14 & 46,6 & 18 & 60 & 32 & 53,3 \\
$50-59$ & 11 & 36,6 & 6 & 20 & 17 & 28,3 \\
Total & 30 & 100 & 30 & 100 & 60 & 100 \\
\hline
\end{tabular}

Source: Medical history, statistical package SPSS 20.0.

Table 3 Predominant exogenous factors, according to $\mathrm{Bi}$ syndrome and treatment group

\begin{tabular}{llllllll} 
& \multicolumn{3}{c}{ Treatment groups } & \multicolumn{2}{c}{ Total } \\
\cline { 2 - 5 } $\begin{array}{l}\text { Exogenous } \\
\text { pathogenic factor }\end{array}$ & \multicolumn{2}{c}{ Group I } & \multicolumn{2}{c}{ Group II } & $\mathbf{n}$ & $\%$ \\
\cline { 2 - 5 } & $\mathbf{n}$ & $\%$ & $\mathbf{n}$ & $\%$ & & \\
Wind & 19 & 63,3 & 21 & 70 & 40 & 66,7 \\
Humidity & 6 & 20 & 6 & 20 & 12 & 20 \\
Cold & 5 & 16,6 & 3 & 10 & 8 & 13,3 \\
Total & 30 & 100 & 30 & 100 & 60 & 100 \\
\hline
\end{tabular}

Source: Medical history, statistical package SPSS 20.0. 
Table 4 Clinical evolution, according to $\mathrm{Bi}$ syndrome and acupuncture treatment

\begin{tabular}{|c|c|c|c|c|c|c|}
\hline \multirow{4}{*}{$\begin{array}{l}\text { Diagnosis } \\
\text { according } \\
\text { to } \mathrm{Bi}\end{array}$} & \multicolumn{4}{|c|}{ Group I } & \multirow{3}{*}{ Tota } & \multirow[b]{4}{*}{$\%$} \\
\hline & \multicolumn{4}{|c|}{ Clinical evolution } & & \\
\hline & \multicolumn{2}{|c|}{ Cured } & \multicolumn{2}{|c|}{ Improved } & & \\
\hline & $\mathbf{n}$ & $\%$ & $\mathbf{n}$ & $\%$ & $\mathbf{n}$ & \\
\hline Wind & 12 & 40 & 7 & 23,3 & 19 & 63,3 \\
\hline Humidity & 2 & 6,7 & 3 & 10 & 5 & 16,7 \\
\hline Cold & 4 & 13,3 & 2 & 6,7 & 6 & 20 \\
\hline Total & 18 & 60 & 12 & 40 & 30 & 100 \\
\hline
\end{tabular}

Source: Medical history, statistical package SPSS 20.0.

Table 5 the clinical evolution of group II treated with a vacuum cup was observed, which shows that, according to $\mathrm{Bi}$ (Wind) syndrome, they were the most benefited with this technique in $63.3 \%$. All patients studied were cured or improved with this treatment

\begin{tabular}{|c|c|c|c|c|c|c|}
\hline \multirow{4}{*}{$\begin{array}{l}\text { Diagnosis } \\
\text { according to } \mathrm{Bi}\end{array}$} & \multirow{2}{*}{\multicolumn{4}{|c|}{$\begin{array}{l}\text { Grupo II } \\
\text { Evolución clínica }\end{array}$}} & \multirow{3}{*}{\multicolumn{2}{|c|}{ Total }} \\
\hline & & & & & & \\
\hline & \multicolumn{2}{|c|}{ Curados } & \multicolumn{2}{|c|}{ Mejorados } & & \\
\hline & $\mathrm{n}$ & $\%$ & $\mathbf{n}$ & $\%$ & n & $\%$ \\
\hline Wind & 19 & 63,3 & 2 & 6,7 & 21 & 70 \\
\hline Humidity & 2 & 6,7 & I & 3,3 & 3 & 10 \\
\hline Cold & 6 & 20,0 & 0 & 0 & 6 & 20 \\
\hline Total & 27 & 89,9 & 3 & 9,9 & 30 & 100 \\
\hline
\end{tabular}

Source: Medical history, statistical package SPSS 20.0.

\begin{tabular}{llll}
\hline Pathogenic factor & \multicolumn{2}{l}{ Treatment groups(cured) } & Total \\
\cline { 2 - 3 } Exogenous & Grupo I & Grupo II & \\
\hline Wind & 40,0 & 63,3 & 103,3 \\
& 41,32 & 61,98 & \\
Humidity & 6,7 & 6,7 & 13,4 \\
& 5,36 & 8,04 & \\
Cold & 13,3 & 20,0 & 33,3 \\
& 13,32 & 19,98 & \\
Total & 60,0 & 90,0 & 150,0 \\
\hline
\end{tabular}

The graph Figure 1 shows the behavior of the treatment efficacy in both study groups, evidence that both acupuncture and cupping were effective in $100 \%$ of the cases

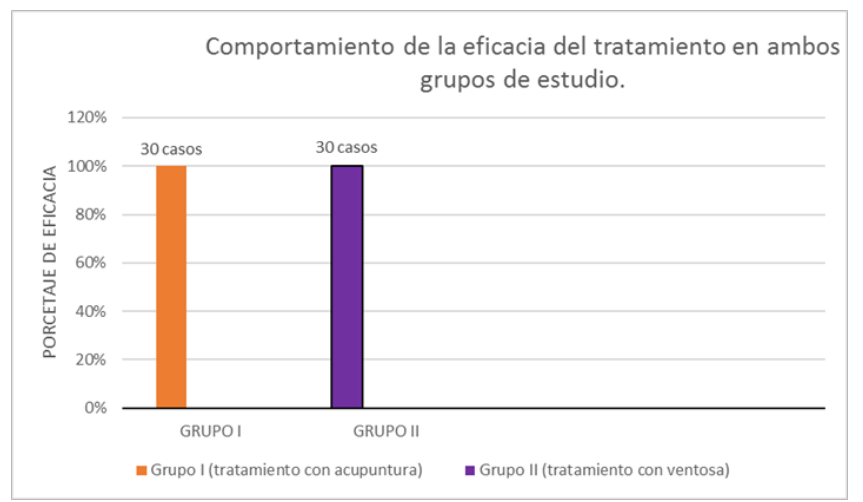

Figure I Behavior of treatment efficacy in study groups I (acupuncture) and II (cupping).

\section{Discussion}

Low back pain is considered a serious health problem in which age and gender for many are two important factors to take into account. Several authors coincide in stating that, with increasing age, degenerative changes appear in the spine, mainly in the sacrolumbar region. ${ }^{7-9}$

In the casuistry, men predominated over women, which coincided with the study carried out by Smith Austin ${ }^{10}$ in Havana, where he found $73.3 \%$ prevalence of men over women; however, Perdomo Martinez, ${ }^{11}$ in Holguín, found a slight predominance of the female sex, with the justification that women attended the physiotherapy room more frequently, where the study was carried out.

There is no doubt that the results obtained in this study are justified by the type of work activity carried out by the men in this population. According to Traditional Chinese Medicine, the essential Qi of the kidneys has an important influence on the growth and development function of the human body.

In men, intemperate sexuality, the abuse of alcohol consumption and excessive work cause kidney energy to decline and lower back pain and its consequences are favored. ${ }^{5}$

In the study, the largest number of patients was between 40-49 years of age, results similar to those reported by Rodríguez Duarte, ${ }^{12}$ González Gámez ${ }^{13}$ and Feria Téllez, ${ }^{14}$ who state that in this group of age, the presence of this disease is more common, in addition to the fact that they have a work relationship with a high load of physical activity, work postures, frequent turns of the trunk, powerful lifting and movements and repetitive work.

Attending to Bi syndrome, Wind was the damaging energy that most affected the patients of the two groups studied, similar results achieved by Díaz Hernández ${ }^{15}$ in Matanzas, with 52\%.

Wind is the most frequent of all external pathogens, typical of spring, with characteristics of being migratory, of acute behavior, which predominates in the study, probably due to the specific climatological characteristics (microclimate) of the municipality.

Acupuncture proved to be a highly effective therapeutic method, since more than $60 \%$ achieved a complete cure of the disease, based on the fact that this therapeutic method is one of the most used in China $^{16,17}$ and also one of the methods oldest known, one of the wonders of nature due to the low cost and accessibility it represents, ${ }^{18}$ and is also used in Cuba with very good results.

In this research, patients with acute low back pain evolved satisfactorily, because through acupuncture the wind, cold and humidity can be toned. In an article by Diéguez Martínez ${ }^{19}$, similar results were found in patients diagnosed with $\mathrm{Bi}$ wind syndrome in $53.3 \%$. In this work, the Bi syndrome due to cold and humidity also resolved, another of the benefits of acupuncture, by improving the cold and eliminating humidity. ${ }^{20.21}$

Among the benefits of the suction cups is to remove or eliminate the wind, which becomes a powerful weapon in the arsenal of Natural and Traditional Medicine, mainly in the conditions produced by this exogenous pathogenic factor, not to mention the assistance in the diseases caused by cold and humidity. This modality, despite eliminating the wind, causes vasodilation, thereby improving blood circulation and energy. ${ }^{22}$

Studies carried out by Chinese therapists showed that the use of fire cupping is one of the modalities of traditional Chinese medicine that produces the best therapeutic effects in osteomyoarticular diseases, including low back pain, because it is capable of eliminating, extracting or sucking the perverse energies of the body. ${ }^{13,23}$ This statement gives solidity to the results obtained in the research, where 
the patients treated with this modality were cured and significantly improved.

\section{Conclusion}

Patients with a diagnosis of acute low back pain responded powerfully to acupuncture and vacuum treatment in all cases, the latter therapeutic modality being the most efficient in curing the cases.

The results show that both alternatives have an acceptable place in the therapeutic arsenal of this disease. Follow-up studies are required to assess the long-term efficacy of these traditional therapeutic modalities.

\section{Acknowledgments}

None

\section{Authorship contribution}

YNC: designed the research, participated in the data collection, in the application of the treatments, clinical evaluation of the patients.

GCG: participated in the research design, participated in the data collection and statistical processing of the data.

HSF: participated in the research design, application of treatments and clinical evaluation of patients.

LRB: participated in the research design, application of treatments and clinical evaluation of patients.

ASS: research design and statistical data processing, clinical evaluation of patients.

All authors approved the final version of the work.

\section{Conflicts of interest}

The author states there are no conflicts of interest.

\section{Funding}

None.

\section{References}

1. Cambell WC. Treaty of orthopedic surgery. 10th edn. Buenos Aires: Editorial Médica Panamericana; 2001.

2. Wong Martínez T, Avello Olivert ME, González Cruz Y. Proposal for a brochure for the prevention of low back pain. Acta Médica Centro. 2017;11(2):74-76.

3. Rivas Hernández R, Santos Coto CA. Management of lumbar pain syndrome. Rev Cubana Med Gen Integr. 2010;26(1):117-129.

4. Alvarez Diaz TA, Lopez Pellon H, Diaz Mastellaris M, et al. Manual for the practice of natural and traditional medicine. Havana: Ecimed; 2014.

5. Kiew Kit W. The Great Book of Chinese Medicine. Barcelona: Uranus; 2017.
6. Yera Nadal JL. Pain medicine topics. Ecimed: Havana; 2017.

7. Soto Padilla M, Espinosa Mendoza RL, Sandoval García JP, et al. Frequency of low back pain and its treatment in a private hospital in Mexico City. Orthopedic Act Mexican. 2015;29(1):40-45.

8. Cruz Jiménez E, Martínez Guerra A, Morejón Barroso O, et al. Acupuncture in patients with acute low back pain treated at the Bararida Comprehensive Diagnosis Center. Rev Intern Acup. 2012;6(1):12-17.

9. Santana Pozo JC, Pestana Pérez N, Bartumeut Rodríguez Y. Treatment of post-stress lumbociatalgia with a hand microsystem. Medicent Electron. 2016;20(1):60-63.

10. Arthur Smith Austin. Efficacy of acupuncture treatment in patients with non-neurological low back pain. Medisan. 2013;17(12):9063.

11. Perdomo Martínez CM, González González A, Perdomo Martínez ZR, et al. Effectiveness of acupuncture in the treatment of low back pain. CCM. 2017;21(1):127-138.

12. Rodríguez Duarte MA, Martínez Delgado N, Valdés Sierra M, Behavior of SOMA diseases treated with acupuncture therapy and its modalities in Bahía Honda. Rev Cub Enferm. 2003;19(1).

13. González Gámez S, Rodríguez Labañino R, Caballero Ordúñez A, et al. A therapeutic efficacy of acupuncture in patients with low back pain. Medisan. 2011;15(3):300-307.

14. Feria Téllez L, Prado Chang Y. Effectiveness of acupuncture in patients with acute low back pain. Florida Emergency Polyclinic. AMC. $2004 ; 8(4)$

15. Díaz Hernández DM, Acosta Mier J, Rodríguez Díaz RI, et al. Treatment of functional low back pain by traditional and natural medicine. Electronic Medical Rev. 2002;24(2)

16. Yu L, Chun Y, Hammes M, Kolster B. Graphic atlas of acupuncture. Representation of acupuncture points. Germany: Hf Ullmann; 2010.

17. Cabana Salazar José A, Ruiz Reyes R. Acupuncture analgesia. Rev Cubana Med Mil. 2004;33(1).

18. Cobos Romana R. Acupuncture, electroacupuncture, Moxibustion and related techniques in the treatment of pain. Rev Soc Española Pain. 2013;20(5):263-277.

19. Diéguez Martínez M, Reyna Carralero JL, Ricardo Santiesteban O, et al. Acupuncture treatment for acute low back pain in high-performance athletes from Holguín province. CCM. 2012;16(2).

20. Lasvi C. Complete course in acupuncture. Madrid: March; 2002.

21. Alonso Menéndez HC, Acosta Buergo JA. Some reflections on the ethics of Medicine Traditional Chinese in Traditional and Natural Medicine in Cuba. Rev Cubana Med Nat Trad. 2016;1(2).

22. Abiague Nicot $\mathrm{C}$. Acupuncture analgesia for low back pain with bamboo suction cups. Medisan. 2011;15(4):420-425.

23. Cuba. Ministry of Public Health. Projections of public health in Cuba for 2015.Havana: Medical Sciences; 2006. 